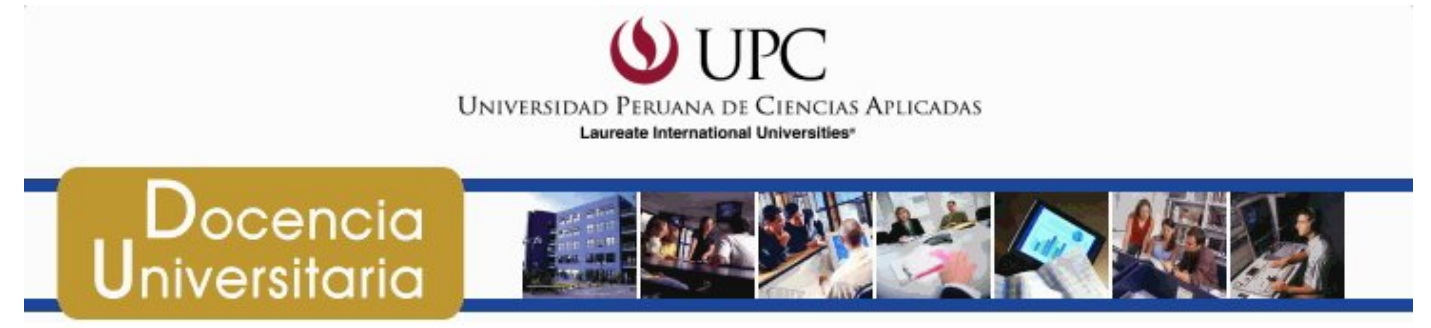

Revista Digital de Investigación en Dacencia Universitaria / Año 4 - Nㅇ- Dic. 2008

\title{
Para una aproximación de la Semiótica Discursiva a la Intersubjetividad profesor-alumno
}

\author{
José David García Contto
}

\section{Resumen}

Este artículo sienta las bases del estudio semiótico de la interacción profesor-alumno, desde la escuela semiótica de Greimas, y algunos representantes contemporáneos como Fontanille y Zilberberg. Desde este punto de vista, se rescatan las principales formulaciones teóricas y sus implicancias en el estudio de la relación que establecen en el aula los protagonistas del "relato" educativo. Ese es, precisamente, uno de los ángulos más saltantes a tener en cuenta en la aproximación semiótica, y es la de considerar el proceso educativo un "relato", que puede ser estudiado y analizado bajo la metodología semiótica.

Entre las conceptualizaciones de la semiótica narrativa, es de particular importancia el concepto de manipulación, porque pone en evidencia las interacciones regulares, así como los simulacros o imagen que se construyen desde cada lado de la interacción sobre el otro (ya sea el estudiante o el profesor). Estos modelos sirven para poner en evidencia también las sensibilidades de cada quien, su punto de vista, e incluso los afectos y pasiones que se intercambian y se construyen en el intercambio entre profesor y alumno. Se trata de un modelo que debe aún ponerse a prueba como instrumento de evaluación didáctica. 
Aก̃̃ 4- NDי- Dic. 2008

\section{Introducción}

Las relaciones entre comunicación y educación tienen larga data y han sido materia de reflexión en diferentes épocas, lugares y escuelas teóricas. La teoría de la comunicación ha sido invocada, ya fuera por los educadores o los comunicólogos, para revisar y ampliar, los estudios sobre educación, generalmente con mira a perfeccionamientos pedagógicos.

La teoría semiótica ha sido también utilizada de modo similar. Sin embargo, esta reflexión no ha dado los frutos teóricos y pedagógicos esperados, pues, muchas veces, la teoría de la comunicación y la semiótica han sido empleadas sin pensar ${ }^{1}$, pese a que "la idea más intuitiva de que la educación es comunicación (aunque de un tipo especial) tampoco puede dejarse de lado." 2

En este trabajo se propone un límite al objeto de reflexión_ se centra en la relación interpersonal que establecen profesores y estudiantes (o educadores y educandos) en sesiones, mejor conocidas como “clases”, en las que el docente realiza (casi siempre) una exposición monológica de un tema (conjunto de objetos cognoscitivos), mientras sus alumnos se limitan a escucharlo y aprender. La importancia de este fenómeno educativo radica en la presencia hegemónica de la metodología clásica en los ámbitos escolares y universitarios (por mencionar los más amplios), ya sea por necesidad o por elección de un sistema pedagógico. Este ensayo busca reflexionar sobre algunos aspectos intersubjetivos de esta relación educativa.

El enfoque a utilizarse está fundado en la Semiótica Discursiva ${ }^{3}$. Su aporte consiste en evitar esa primera aproximación, planteada antes como relación interpersonal, para trabajar, más bien, una intersubjetividad, en la que la categoría “sujeto” acerca a los “roles” que producen (y/o que se producen en) dicha relación.

Entonces, ¿cuál es el ángulo desde el que esta teoría puede enfrentar el fenómeno educacional? Paul Ricoeur, un importante filósofo y hermeneuta, propone la idea de que

Rodríguez Illera 1988:.13-14.

Ibídem: 18

Se entiende por Semiótica Discursiva a la corriente que, heredera de la Semiología de Saussure, dio lugar a un complejo modelo de estudio y análisis: El Recorrido Generativo de la Significación, desarrollado por Greimas, y ampliado al estudio de los discursos y sus estructuras, por la Escuela de París. Actualmente, dicha escuela semiótica es muy activa, particularmente en Francia, Bélgica, México, España y Brasil, entre otros países. Greimas fundó su modelo en el estudio de relatos, historias o cuentos: a este primer desarrollo se le conoce como Semiótica Narrativa. Son las aproximaciones contemporáneas las que le han dado un giro importante a la Semiótica Narrativa, convirtiéndola en un estudio sistemático de discursos. 
Aก̃̃ 4- NDי- Dic. 2008

las acciones son discurso: la vida es un relato ${ }^{4}$. Puesto que las acciones y hechos cotidianos son pensados en términos de relatos, y la Semiótica Narrativa es un modelo de análisis de los mismos, es posible plantear un análisis del fenómeno educativo como narración. Es decir, el planteamiento del presente trabajo es analizar a acciones y sujetos en tanto son "narrados" por ellos mismos, aproximándose al discurso del fenómeno educativo ${ }^{5}$.

Queda así en evidencia un supuesto inicial: si bien la Semiótica Narrativa se ocupa inicialmente de las acciones "del papel” (contadas en cuentos, historias, novelas o crónicas), es posible concebir el fenómeno educativo también como un relato. Por medio de entrevistas, es posible que los "protagonistas" construyan una historia, una narración de su propia experiencia ${ }^{6}$. Metodológicamente, se trata de una extrapolación de estos modelos sobre la vida cotidiana, procurando enfrentar "situaciones reales de la vida social misma", y aplicándolos a la interacción profesor-alumno.

El principal aporte de la Semiótica Narrativa al estudio de la educación como comunicación, será buscar una estructura subyacente ${ }^{7}$ formal a la relación entre educador y educando, explicando la operatividad relacional que da sentido a los hechos producidos a diario en las aulas de clase:

\section{"La exploración semio-narrativa del discurso didáctico tiene por meta hacer emerger la organización formal que comporta el ejercicio de esta práctica discursiva particular" (Vincensini 1987: 9)}

En tal sentido, es necesario aprovechar la metodología y la riqueza del marco conceptual semiótico para abrir una nueva línea de investigación en el discurso didáctico y en el discurso del aula. En este ensayo, las entrevistas tienen como propósito

$4 \quad$ Los siguientes títulos del autor dan una clara pista de su propuesta: "Hermenéutica y acción; de la hermenéutica del texto a la hermenéutica de la acción” (Buenos Aires, Ed. Docencia, 1985, 222 pp.), y "El discurso de la acción” (Madrid, Cátedra, 1981, 154 pp.) Sin embargo, en estos textos, Ricoeur proyecta la reflexión sobre las implicancias del postulado que, para propósitos de la presente investigación, es asumida. La crítica sobre el postulado de que las acciones pueden ser tomadas como texto, son dejadas para un debate posterior. Pero este supuesto permite deducir que, si las acciones son texto, es posible analizar las acciones en tanto son convertidas en texto.

5 Se postula el fenómeno como discurso. Esto tiene relación con la postulación de una construcción social de la realidad. Realidad que no es sino discurso, sobre el fenómeno o lo real siempre inasible directamente.

6 Latella 1988: 253.

7 "Para la semiótica, más que el análisis directo de los comportamientos empleados para expresar distintas acciones, interesa poner de manifiesto las estructuras subyacentes más profundas, que los hacen operativas.” Latella, Graciela. Op.Cit. Pág. 254.

$8 \quad$ La traducción es responsabilidad del autor del presente estudio. 
Aก̃̃ 4- NDי- Dic. 2008

ser ejemplos metodológicos, no recursos para generalizaciones inductivas sobre el fenómeno educativo.

\section{La Educación es Manipulación}

En la Semiótica Narrativa, la manipulación tiene como definición modal "hacer-hacer”, o, simplemente, "hacer que otro haga”. Visto así, desde el chantaje más elaborado hasta el favor más sencillo, son considerados manipulación. La educación no escapa a este esquema, aunque los “haceres” de carácter cognoscitivo (explicar, exponer, aprender, conocer, identificar, explorar, reconocer, indagar) sean verbos frecuentes en los sílabos de educación superior.

Según esta teoría, la manipulación supone a un manipulador y a un manipulado, y asigna a cada posición los roles necesarios. La función del manipulador es persuadir, mientras que la del manipulado interpretar.

El "hacer persuasivo" en la manipulación es necesariamente un "hacer-creer". En otras palabras, impulsar un "hacer” (cualquiera que este sea) implica que el manipulado interprete o no algo: su decisión supone un "creer" o un "no creer”. La aceptación es el ejercicio de una interpretación. Por ello, no existe manipulación sin "hacer-creer” o sin un "creer” correlativo.

\section{Persuasión e Interpretación como ejercicio del Creer}

El ejercicio del “creer” se presenta al nivel de las axiologías que buscan que el educando se adhiera; es decir, cuando se le lleva en conjunción a determinados valores (ideologías de lo correcto, propio, bueno, útil o necesario, variables según la cultura). Por otro lado, en el ámbito de los saberes transmitidos también existe manipulación, pues se busca que el alumno crea que lo que se dice es verdad. Tanto las axiologías (valores), como los saberes, son sometidos a la decisión de creer o no creer. Esta decisión implicará (según la clase o curso en cuestión) una ejecución: hacer algo consecuente con esa creencia. En Matemática, por ejemplo, si el estudiante "cree” en los postulados matemáticos dados por el educador, resolverá los problemas asignados en función a estos.

Es, entonces, pertinente para la actividad educativa explorar el "hacer" persuasivo e interpretativo como un "hacer" regulado por la modalidad del "creer", que, en realidad, matiza cualquier tipo de comunicación humana ${ }^{9}$.

9 "Si asumir la palabra de otro es, en cierto modo, creer en ella, entonces el hacerla asumir significa decir para ser creído. Así considerada, la comunicación (como uno se lo imagina un 
Aก̃̃ 4- NDי- Dic. 2008

En semiótica, la comunicación es definida como un "hacer" cognoscitivo, marcado por dos niveles: uno de transmisión de un "saber” (más superficial, de tipo emisor - mensaje - receptor), y otro marcado por el "hacer-creer" (más profundo, que implica persuasión e interpretación). Greimas reitera esto y abre las consecuencias del “creer”:

“(...) al menos en un primer acercamiento (a la comunicación), puede ser calificada de simple: se tratará, en este caso, del hacer informativo que, teniendo en cuenta el esquema de la comunicación, aparecerá como hacer emisivo o como hacer receptivo. Sin embargo, la mayoría de las veces -aunque no siempre-, la transferencia de saber está modalizada desde el punto de vista veredictorio: con relación al eje destinador-destinatario, se tendrá, respectivamente, el hacer persuasivo y el hacer interpretativo que ponen en juego una relación fiduciaria intersubjetiva". (Greimas 1982: 59)

Por ende, existe una consideración diferenciada entre el modelo de transmisión y el modelo de manipulación de la comunicación:

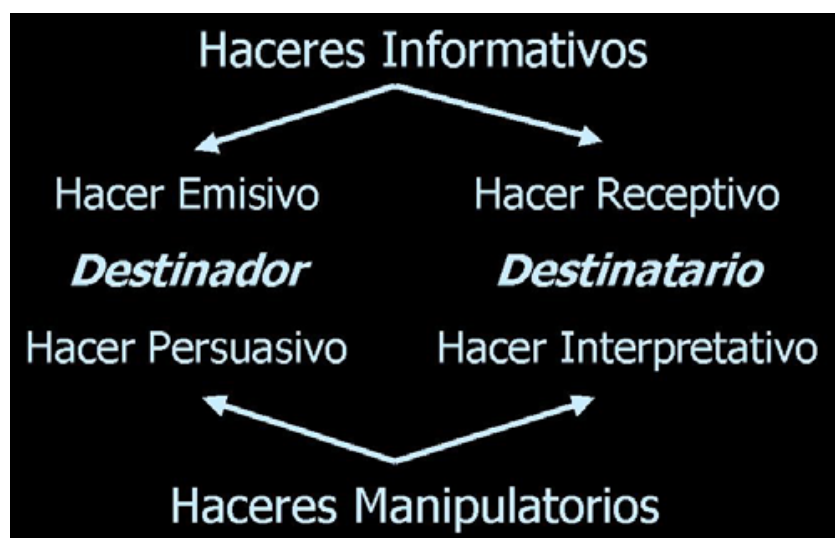

La persuasión e interpretación son una consecuencia necesaria del “creer". Es una relación de confianza entre los sujetos de la interacción comunicativa. Sobre la base de un eje comunicativo, se puede modalizar a cada actante (emisor, receptor) con el “creer”. Así, para confiar en el destinador, tendrá que verse, en primer lugar, su

poco apresuradamente) es menos un hacer-saber que un hacer-creer y un hacer-hacer." (Greimas-Courtes 1982 : 75). 
Аก̃̃ 4- Nㅣ- Dic. 20008

credibilidad. Modalizando al objeto (y su relación con el mundo), se apreciará la verosimilitud. Finalmente, en relación al destinatario, se observará su credulidad ${ }^{10}$.

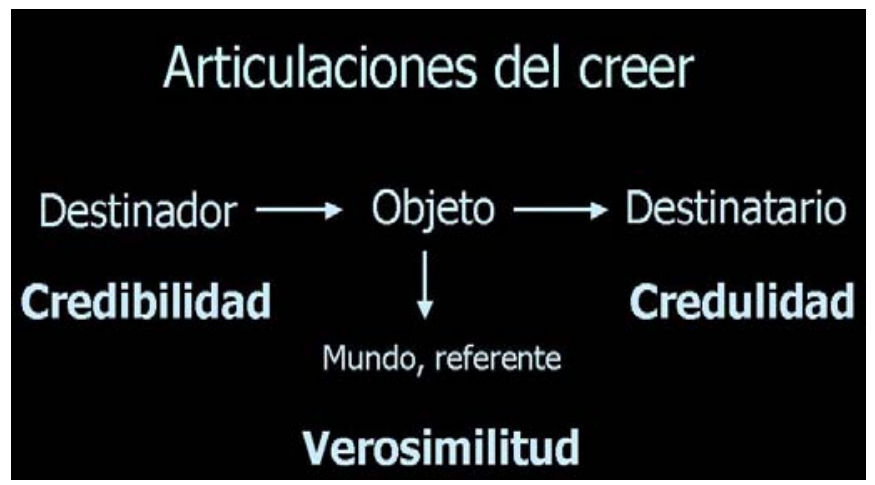

Por ello, al enfrentar una clase cualquiera, la credibilidad del docente está en juego. Como se vio anteriormente, su pertenencia a un sistema institucional lo pone en el vértice del cono de poder. Este otorga, desde el inicio de la actividad educativa, una autoridad y un grado elemental de credibilidad (el docente "debe ser creído" porque es el profesor y se supone que sabe). Por esta misma razón, el alumno se halla en una posición de “deber-creer”. Ambos ejercicios del “creer” están en consonancia con que la clase (lo que dice el profesor, el objeto cognoscitivo) sea verosímil. En otras palabras, si un docente dijera una locura (o algo no creíble, inverosímil) pondría en tela de juicio su credibilidad, despertando un conflicto en el alumno (entre el "deber-creer" y su incredulidad). Estas tres variables (credibilidad, verosimilitud y credulidad) se hallan en constante tensión. Más aún en la educación superior, en la que, se supone, el alumno tiene la capacidad de dudar; es más, es invitado a criticar y poner a prueba la verosimilitud de lo dicho en clase (teorías, propuestas, ciencia, opiniones).

\section{Fiducia: Creencia y Confianza}

En la relación educativa (como en cualquier comunicación), están en juego el “creer” y el "saber". Ya Greimas propuso que estas dos modalidades conforman el mismo universo cognitivo $^{11}$. En tal sentido, es necesario tratar de entender sus relaciones en el campo de la comunicación educativa. Desde diversos ángulos, el "saber" precede al "creer”, y viceversa. Es importante recalcar cómo el "saber" se construye sobre la base del "creer". En otras palabras, todo "saber" (certeza) se funda en algún tipo de creencia: en una fe, una confianza, una fiducia ${ }^{12}$. Esto es particularmente pertinente en la circulación del objeto

Landowski 1989: 206.

Greimas 1989 : 130 - 154.

Fontanille y Zilberberg 1998 : 197-199. 
Aก̃̃ 4- NDי- Dic. 2008

cognoscitivo en la comunicación educativa. Fontanille y Zilberberg proponen, en dos versiones, una doble orientación de la fiducia: ${ }^{13}$

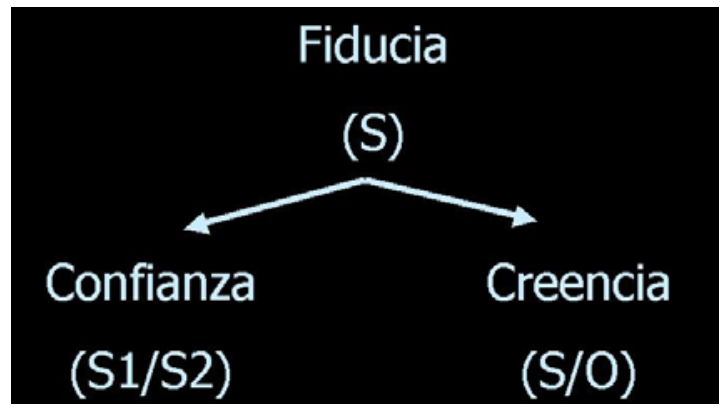

En una versión, la confianza es la orientación intersubjetiva de la fiducia (en este caso, del alumno hacia el profesor), mientras que la creencia es la orientación del sujeto a un objeto. Recálquese, entonces, que no se trata de una "confianza en la persona”, sino de la confianza depositada en aquel que desempeña el rol de profesor de un curso. Así, no es analizable la confianza íntima y personal (que supondría una amistad), sino la mínima confianza que el educando orienta hacia el profesor, que hace posible la relación de enseñanza-aprendizaje.

Por ende, la confianza (antes del "saber" mismo) se establece, en principio, sobre el docente, por la autoridad que le es conferida desde el sistema educativo . Por esta razón, lo que diga es "confiable", siendo esta la base que construye la "creencia” del educando sobre la materia u objeto de saber. Además, esta confianza (ejercida por el alumno hacia el docente) se ve reafirmada o amenazada por el desempeño del profesor. Cabe decir que la competencia cognoscitiva del docente afecta y modula el "creer" del alumno (su credulidad). Sin embargo, tal parece que el "saber” en sí mismo no siempre se ve afectado por dicho desempeño; es decir, existe una relación gradual al respecto. Un profesor tendría que ser muy incompetente o muy desequilibrado para que el conocimiento que brinde no sea verosímil; más bien, le despertaría duda y desconcierto (su credibilidad quedaría demasiado comprometida). Aún peor debería ser el profesor, para que el "saber" en circulación sea, de plano, rechazado por el alumno. En ese sentido, puede decirse que, de acuerdo a su continua performance, el docente construye la credibilidad de sus siguientes clases. Y dicha credibilidad solo se ve afectada cuando la confianza entra en extrema tensión.

Metafóricamente hablando, el docente, como destinador preponderante de la comunicación educativa, empieza el curso con un capital de credibilidad. Este se acrecienta, sostiene o disminuye de acuerdo a la evaluación y juicio (sanción) que hacen los alumnos

13 Ibídem. (La traducción es responsabilidad del autor de este ensayo). 
Aก̃̃ 4- NDי- Dic. 2008

continuamente de sus clases (performance). Esta evaluación, por ende, es un "creer" sobre la capacidad y verosimilitud del docente. La verosimilitud máxima confiere al objeto de “saber” un grado estable de creencia, dándole al alumno certeza sobre el mismo; ello permite, finalmente, el estatuto de conocimiento.

Pero no siempre la confianza es proporcional a la verosimilitud del objeto de valor, o a la credibilidad. Si bien la confianza hacia el docente (así como la que el profesor le tiene al alumno) se convierte también, por sí misma, en un valor modal, en ocasiones esta y la verosimilitud marchan separadas.

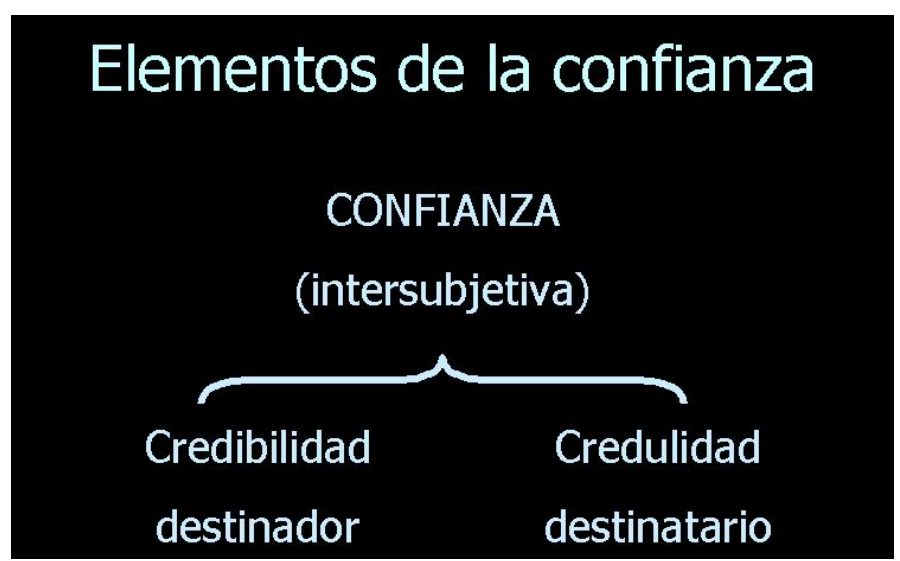

\section{El Contrato Enunciativo y los Simulacros Modales}

No pueden desarrollarse la persuasión e interpretación en la dimensión cognoscitiva, si antes de establecer ese tipo de "hacer" no existe alguna relación previa que funde la posibilidad de relación comunicativa: el contrato.

El contrato fundador de la relación intersubjetiva es denominado como "contrato implícito”. Graciela Latella lo explica con detalle:

“(.. ) el acto cognosctivo de reconocimiento por el cual un sujeto semióticamente competente construye al sujeto - otro o a su antisujeto al mismo tiempo que se construye a sí mismo. Pero siendo este reconocimiento de orden del simulacro, es solo a consecuencia de una aceptación de simulacros como los sujetos son capaces, recíprocamente, de asumir la relación modal. Es solo entonces cuando los sujetos van a fundar verdaderamente una relación intersubjetiva (que ya no es un simulacro) (..).” (Greimas y Courtes 1991: 34) 
Antes de establecer la relación intersubjetiva, el juego de representaciones es fundamental para el desarrollo de la misma. Las posibilidades de simulacro son varias; por lo tanto, la conformidad o no-conformidad sugiere también simulacros tensivos sobre un fondo no estable. En el caso de la no-conformidad, un conflicto extremo podría ocurrir si un "sujeto-otro, al no responder a la expectativas interaccionales del sujeto, no ha construido un simulacro por su lado; este sería el caso, por ejemplo, del indiferente"14. Se observa, además, que las expectativas son un elemento importante en la verificación mutua de simulacros. Finalmente, lo que se crea de un sujeto, o de un sujeto-otro, dependerá también de lo que se espera que estos digan o hagan ${ }^{15}$.

Si bien, como se vio en la cita previa, existe un reconocimiento cognoscitivo, Greimas y Fontanille sugieren que también podría darse en el nivel pasional ${ }^{16}$. Además, indican que, al extraer todas las consecuencias del análisis de las pasiones, sería necesario "postular que toda comunicación es comunicación (e interacción) entre simulacros modales y pasionales: cada quien dirige su simulacro hacia el simulacro de otro, simulacros que todos los interactantes y las culturas a las que pertenecen han contribuido a construir"17.

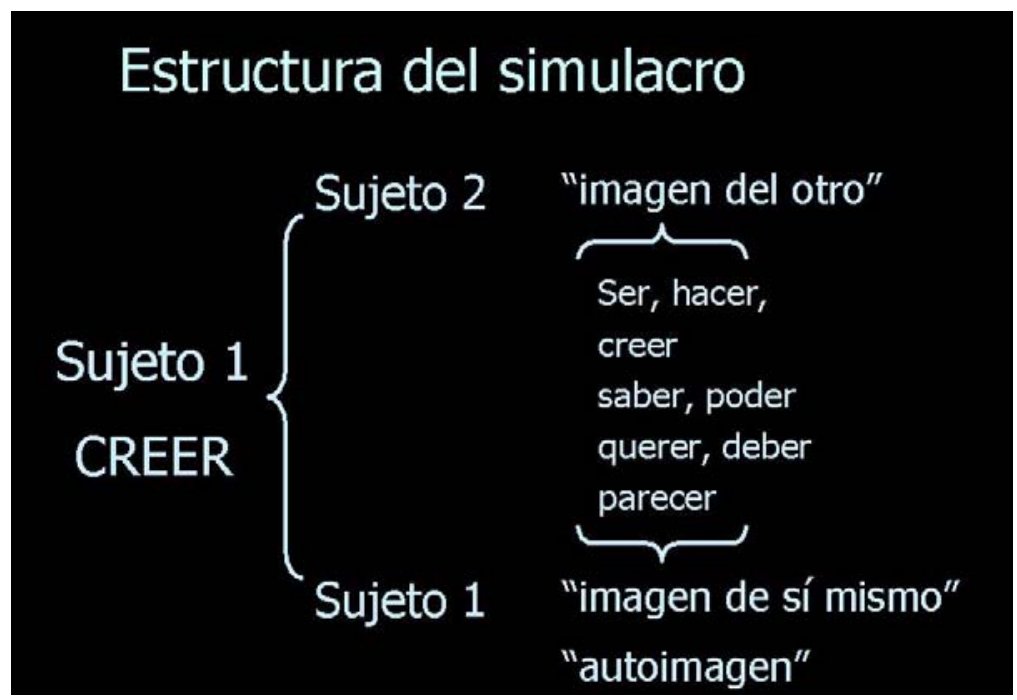

Se puede explicar esta cotejo de representaciones (simulacros modales, como los llamara Greimas) a través de los esquemas de la inmanencia (ser - no ser) y de la manifestación

\footnotetext{
Greimas y Courtes 1991: 34

La noción de "espera” ya apareció como fundamental en las primeras aproximaciones de la escuela greimasiana a las pasiones. Véase el ensayo de Greimas: De la Cólera, en Del Sentido II. Gredos, Madrid. 1989. pp. 255 - 265.

16 Greimas y Fontanille 1994: 52-57.

17 Ibídem. : 56.
} 
Aก̃̃ 4- NDי- Dic. 2008

(parecer - no parecer) de las modalidades veridictorias ${ }^{18}$. Entonces, la construcción de los simulacros modales se articula sobre el "creer-parecer" del sujeto sobre el sujeto-otro. Al verificar la conformidad de sus simulacros, los sujetos (aún virtuales) de la interacción operan el "reconocimiento" y construyen un "creer-ser" sobre el otro sujeto, ya con elementos de juicio otorgados por el primer acercamiento. En este punto, las investigaciones no permiten precisar cuál es la relación entre este "creer-ser" sobre el sujeto y el “creer-decir-verdad" del sujeto. Este punto de "aceptación mutua de la conformidad de los respectivos simulacros”, en el que se conjugan las modalidades de la veridicción, puede ser el origen de los "haceres" persuasivo e interpretativo. El "hacer" persuasivo corresponde al "hacer-creer-verdad", mientras que el "hacer" interpretativo al "creerverdad”. Ambos "haceres" cognoscitivos se entrecruzan al ser ejercidos por los sujetos de la interacción.

\section{Simulacros Figurativos y Sensibles}

No obstante de que esta perspectiva modal y narrativa es útil para aprehender la interacción de simulacros, el alumno y el docente difícilmente se perciben mutuamente de esta forma, ya que "los simulacros de los actores en interacción son esencialmente disposiciones de sujetos modales figurativizados y sensibilizados”"19. Es decir, no solo se trata de una actividad cognoscitiva, sino, fundamentalmente, de las sensibilidades de un sujeto frente a otro, y de la aprehensión perceptiva de su figuratividad (complexión física, voz, olor, vestimenta, etc.),. Con esta última, el sujeto sensible construye un simulacro y representación no solo de su posible competencia cognoscitiva, sino también de su ser individual $^{20}$.

Los simulacros, por ende, representan el universo de percepciones de un sujeto sobre el otro, tanto figurativa como modal y narrativamente. Así, por ejemplo, todo lo que un alumno imagina sobre un profesor de filosofía (cómo se ve, cómo habla, si usa barba o no, su trato al estudiante, etc.) será parte de este simulacro inicial, previo al primer encuentro y al comienzo de la interacción. Este simulacro puede ser verificado, o reformulado, para adaptarse a la figuratividad y performance reales del docente.

18 El cuadro de la veridicción es un cuadro semiótico, que lleva en sus esquinas, respectivamente, el SER opuesto al PARECER en el lado superior, y el NO PARECER opuesto al NO SER en el lado inferior. Este cuadro pone en evidencia la lógica y la relación entre aquello que ES y aquello que PARECE, y cómo se combinan en relación a un mismo objeto o sujeto.

19 Greimas y Fontanille 1994: 56.

20 Resulta inevitable preguntarse cómo afecta esta percepción figural mutua a la construcción del simulacro de la competencia cognoscitiva del otro. Así, observar a un alumno desaliñado puede llevar a un docente a plantearse el simulacro de ese alumno como "vago" o "poco inteligente". 
Aก̃̃ 4- NDי- Dic. 2008

\section{Un simulacro recurrente sobre el alumno}

Fabbri expone un simulacro que es recurrente, desde la perspectiva del profesor, en la interacción educativa:

“(...) el pedagogo no podría presuponer en el receptor una competencia receptiva constante. Tal como es construido en el discurso del enseñante, el enseñado aparece, por el contrario, como un sujeto desprovisto del poder, del querer, del saber y del deber receptivos. El discurso didáctico va, pues, a utilizar toda una panoplia de actos ilocutorios y de maniobras semióticas (provocaciones, seducciones, etc.), intentando (re)-construir esta competencia amenazada permanentemente. En una palabra, el contrato de transmisión, supuestamente frágil, debe ser constantemente reactivado con la ayuda de procedimientos de captación (despertar la atención, solicitar la curiosidad del auditorio, etc.)” (Fabbri 1979: 30)

Fabbri considera que este es un simulacro generalizable a la actividad del maestro. Apunta que las maniobras didácticas son estrategias narrativas (que provoquen y seduzcan), pasionales (que busquen la curiosidad del auditorio), y figurativas y sensibles (cambios en el tono de voz, movimientos bruscos, gestos inesperados), también denominadas como "despliegue escénico”. Algunos aspectos de este ejercicio histriónico y del "hacer” pedagógico del docente son desagregados líneas abajo.

En suma, estas estrategias didácticas (manipulatorias) del docente se realizan sobre la base de una representación, que es la de la fragilidad de la atención y la disposición a aprender del alumno. De forma recíproca, el estudiante puede simular que atiende ("hacer-creeratender"), presentando así un simulacro al docente. Este "atender” se manifiesta figurativamente en "observar” y "escuchar” aún cuando su atención se encuentre en otra parte. Este juego de simulaciones, presentadas de ida y sostenidas de vuelta, representan una cierta equidad en la interacción profesor-alumno, pues ambos realizan e interpretan simulacros.

\section{La Sanción Didáctica}

En la Semiótica Narrativa, la sanción corresponde a la retribución que otorga un destinador en función de la performance realizada: la recompensa o el castigo. Esta performance es evaluada de acuerdo a un contrato (entre manipulador y manipulado). Si bien la recompensa y el castigo aluden a un aspecto práctico (sanción pragmática), es necesario 
Аก̃̃ 4- Nㅣ- Dic. 20008

fundarlas en un ejercicio cognoscitivo. La sanción cognoscitiva, en cambio ${ }^{21}$, es un juicio (sobre el destinatario), una modalización del “creer” sobre el “ser” del destinatario.

Por ello, se tiene un "creer-ser" (un simulacro sobre el educando) formulado como juicio y sanción cognoscitiva, y un "creer-ser-hacer” (sobre su performance) en el mismo curso.

En base a la performance del alumno a lo largo del proceso educativo (los actos programados), el docente evalúa, juzgando cada acto con un juicio “creer-hacer-bien” o "creer-hacer-mal” (y los matices intermedios). Sobre la sintagmatización de estos actos (del alumno), y los juicios del docente, es que se construye un "creer-ser" sobre el educando. El profesor opera el ejercicio del "creer” (una interpretación) sobre las acciones de los estudiantes (performance) para desarrollar un juicio epistémico de cada uno de ellos (el "creer" se convierte luego en un "saber-ser" sobre el educando). A lo largo del proceso educativo, este "creer-ser” se modifica o ratifica conforme a sus actos, influyendo, a su vez, en el juicio sobre estos (sintagmáticamente posterior) que realice el alumno.

En conclusión, al inicio de un curso, los alumnos son "sospechosos" para el docente: es decir, son sujetos de un simulacro asignado por él, ejercido sobre el "parecer" inicial de estos. Ergo, se asignan inicialmente "sospechas" ("aquel parece buen alumno", "ese otro parece flojo", "ese parece inteligente”, etc.) Tal como se discutiera anteriormente, el profesor postula estos simulacros, que son verificados o desmentidos de acuerdo a la performance cognoscitiva del alumno.

\section{Límites para la sanción desde el docente}

La evaluación del docente sobre la actividad del alumno se realiza sobre un determinado límite cognoscitivo. Recuérdese que (en general), al hablar de la actividad del educando, se trata de un ejercicio fundamentalmente cognoscitivo. La carencia a llenar en el estudiante es una de orden del "saber" y es (o se supone) mensurable ${ }^{22}$. La sanción tiene como límite su propio contrato fundador. Así, cuando el docente desarrolla un curso, se plantea una serie de objetivos pedagógicos a lograr; en otras palabras, saberes precisos a adquirir por los estudiantes.

Las pruebas o exámenes que programa tienen como propósito medir o calcular saberes específicos en el educando; saberes que son definidos de antemano, de los que carece al inicio del proceso, y con los cuales debe conjuntarse al final del mismo.

21 “... es un juicio epistémico sobre el ser del sujeto y, más generalmente, sobre los enunciados de estado que este rige gracias a las modalidades veredictorias y epistémicas” Ibídem. (¿CUÁL ES LA CITA?)

22 Tal como propone Fontanille en su análisis sémico del /saber/, al afirmar que se trata de objetos directos (Fontanille 1987b: 28). También lo hace en su ensayo "Propuesta para una tópica de carácter antropomorfo" (Fontanille, 1994. pp. 176). 
El objetivo pedagógico es la competencia (generalmente cognoscitiva) que el alumno debe adquirir durante el proceso. Ese es el límite planteado para la sanción. Se pronuncia un juicio solo sobre el saber adquirido por el alumno. Ahora bien, esta competencia debe convertirse en performance (en acto) para ser observada por el docente: "Así pues, un objetivo no es operacional a no ser que corresponda a una actividad concreta, si define un 'comportamiento observable': no se trata ya más de competencia, sino de performance,"23. De esta manera, las evaluaciones proporcionan un acto planificado y controlado por el docente para que el alumno ejercite la competencia adquirida.

Prácticamente, todas las performances programadas por el docente son calificadas sobre una escala numérica en la cual, por ejemplo, la cifra más alta corresponde a una sanción pragmática de recompensa; es decir, por su cercanía a la performance óptima preestablecida. Esta calificación se realiza según algún contrato previo de lo que se considera "buena performance". De no estar claro para el docente y el alumno, generará conflicto entre ambos (un desacuerdo sobre el juicio que representa la nota, y el valor de la performance evaluada). Estas calificaciones tienen un carácter veredictorio: permiten al educador acercarse a "saber sobre el ser del saber" ${ }^{24}$ en el alumno (tomando como supuesto que el educando rinde "lo mejor que puede"). En base a este tipo de metasaber (ya que se trata de un "saber - saber", S2 saber [S1 alumno saber]) ${ }^{25}$, el docente establece y reconoce al alumno que "sabe" y al que no, lo que invita inmediatamente al docente a juzgar (sancionar) aquellos estados evaluados. Así, "el que sabe” es un "buen alumno” y "el que no sabe” es un "mal alumno”. Este juicio desencadena la sanción pragmática: la nota o calificación numérica antes descrita.

Por supuesto que esta primera aproximación aparece como maniquea. Ya que no se trata de evaluar la "bondad" o "maldad" morales o éticas sino que los términos bien y mal son aplicados dentro del ámbito (isotopía) de la eficiencia y desempeño del alumno en relación a las evaluaciones propuestas por el docente. La alta eficiencia, y buen desempeño cognoscitivos (generalmente) suponen necesariamente una nota (numéricamente) alta, y la poca eficiencia o mal desempeño una nota baja.

Puede apreciarse que la sanción sobre el alumno está sujeta a una metodología: debe tener un “rigor académico”. Está sujeta a la deóntica del proceso (“deber-ser”) establecida por la institucionalidad del sistema educativo y social, coerciones que forman parte de la especificidad del contrato pedagógico. Esta evaluación no debe efectuarse afectivamente (influida pasionalmente), ya que las sanciones podrían no corresponder al contrato

Ibídem. La traducción es responsabilidad del autor de este trabajo.

S2 saber ser [S1 saber (ser/hacer)]. (EXPLICAR!)

También llamado “saber metasemiótico” en Fontanille 1987b:. 42 - 44. 
Aก̃̃ 4- NDי- Dic. 2008

educativo, atentando contra la objetividad y/o justicia de las calificaciones. A su vez, el alumno, al recibir la nota, "sanciona” la sanción del docente: evalúa su justicia, de acuerdo al contrato educativo. En primer lugar, reconoce si es o no la calificación que, según contrato, le corresponde (actúa como juez de su performance), se autosanciona, y luego coteja con la sanción de la nota. Según este cotejo, reconoce al educador como "justo” o “injusto” (sanción cognoscitiva).

Los juicios ejercidos por el docente son diversos. Por ello, se propone un listado (no exhaustivo) de ejes sobre los que se pueden ejercer sanciones, algunos sistematizados por la deóntica del sistema educativo, o, en ocasiones, por la deóntica particular de algún profesor en el ejercicio didáctico (recuérdese que se trata de "pareceres" desde el docente):

\section{Ejes de sanción desde el docente}

- Eje de la competencia temática (relativa a objetivos pedagógicos).

- Eje de la evaluación de su competencia receptiva (atención o distracción).

- Eje de la competencia lingüística (uso de lenguaje).

- Eje de la competencia semántica (saber enciclopédico o universal; cultura general).

- Eje de la habilidad intelectiva (rapidez de comprensión).

- Eje de la creatividad (en la comprensión y uso de los saberes, y en la resolución de problemas).

- Eje de la laboriosidad y el esfuerzo.

- Eje del comportamiento social.

- Eje afectivo del docente (agrado, desagrado, simpatía o antipatía).

Cabe notar que cada eje amerita un estudio cuidadoso. Desde la psicología, existen pruebas formuladas y validadas para medir cada uno de estos ejes. No obstante, parece hacer falta una visión holística que integre cada uno de estos aspectos en un sistema que comprenda las diferentes variables involucradas en este "sentir" del docente sobre el alumno.

\section{Sanciones o juicios por parte del educando}

Por otro lado, desde el sujeto "protagonista” del proceso educativo (el alumno), existe también un ejercicio de sanción (del "creer”) sobre el "hacer-hacer” y el "hacer-creer” del docente. El educando sanciona el "buen o el mal hablar" del docente (en este caso, su competencia lingüística, por ejemplo), o si es “aburrido” o “interesante”, como juicio de valor (pragmático, ético, o patémico). Sobre el "ser” del educador, evalúa (“cree”) su personalidad ("buena gente” o "poco amable”), ya como juicio cognoscitivo. Todo este entrecomillado alude, pues, a un recorrido figurativo expandible temáticamente por varios 
Aก̃̃ 4- NDי- Dic. 2008

ejes, que tienen dos extremos: uno siempre positivo (eufórico) y el otro negativo (disfórico). De forma general, se resume las características de "buen profesor" y "mal profesor”. También se incluyen rasgos figurativos, como "no se entiende lo que dice”, "sus exámenes son fáciles”, "pide muchos trabajos”, "exige mucho" e, incluso, "cree que su curso es el único que existe”, aludiendo a un exceso en sus exigencias didácticas.

La sanción del alumno no solo depende de la performance receptiva del discurso del docente. Depende también del simulacro que se haya forjado el educando del educador, de las atribuciones factitivas, modales, sensibles y patémicas (emocionales) en su representación. En otras palabras, el alumno espera una competencia por parte del profesor, tanto a nivel cognoscitivo como a los aspectos más sensibles y primarios (su timbre de voz, su entonación, apariencia física, su gestualidad, etc.). A partir de estas expectativas, el alumno contrasta con el "ser" (modalizaciones calificativas) del docente y con el "hacer ser” (la ejecución de la “cátedra”), generando un juicio (sanción) en los diferentes ejes de su presencia y de su performance.

Puede afirmarse que la sanción del docente está controlada por una sintaxis deóntica del proceso, mientras que del educando se encuentra "libre”, no sujeta a esta, aunque sí a una particular: la de sus propias axiologías e ideologías, sobre las que se fundan sus juicios éticos.

Los juicios ejercidos por el alumno son diversos. Por ello, se propone, como en el caso anterior, un listado de ejes de sanción:

\section{Ejes de sanción desde el alumno}

- Eje del dominio temático.

- Eje del ejercicio evaluatorio (cómo califica el profesor).

- Eje metodológico (la programación de temas, objetivos y evaluaciones).

- Eje de la exigencia (qué tan exigente o no es el profesor).

- Eje de la claridad expositiva (modo de explicar un tema y hacerlo comprensible).

- Eje de la animación (“entretenido” o “aburrido”).

- Eje del comportamiento social.

- Eje afectivo desde el docente (agrado, desagrado, simpatía o antipatía).

\section{Sanciones de lo sensible}


Aก̃̃ 4- NDי- Dic. 2008

Las innovaciones en la semiótica discursiva, realizadas en los noventa, expandieron el estudio semiótico al de las pasiones y sensorialidades en el discurso ${ }^{26}$. Bajo esa premisa, es necesario repensar la manipulación y la sanción como fundadas en sensaciones de los protagonistas de la interacción educativa. Se proponen, por ello, algunos campos en la sensibilidad de esta interacción a modo de listado no acabado y aún por trabajar. Servirá para poner en evidencia la urgencia de perseguir esta línea de investigación. Por su presencia en el ámbito del salón de clases, se desarrollan los ejes con un enfoque desde el alumno que observa la performance del docente.

- Eje de la entonación (y el timbre de voz)

La voz tiene varios matices que la modulan en tanto presencia. Uno de estos es el timbre de voz; en otras palabras, la sonoridad propia y única de aquel que habla. Así, se tienen voces agudas, graves, duras, secas, dulces, ásperas, suaves, opacas, brillantes, nasales, quebradas, enérgicas, etc. Cabe aclarar que el timbre de voz es un matiz que, generalmente, no es modulado concientemente por el profesor; más bien, es una propiedad "natural” de su corporeidad manifiesta (aunque, eventualmente, algunos docentes modulan su timbre con propósitos didácticos). De alguna manera, se proponen intuitivamente ejes sensibles: agudo-grave, áspero-suave, opaco-brillante, quebrado-enérgico; estos suponen una continuidad de matices intermedios.

La entonación, a diferencia del timbre, es un matiz que, habitualmente, es más controlado por el docente. Pueden identificarse, al menos, dos aspectos en la entonación: el ritmo y la altura. El ritmo es la rapidez o lentitud al hablar: este aspecto vocal afecta directamente la presencia del objeto de saber (su extensión discursiva, por ejemplo). La otra variable, la altura, es la fuerza de la voz; es decir, el volumen (incluso mensurable en decibeles). Estos matices son también susceptibles de proponer en ejes continuos, desde "hablar rápido" hasta "hablar lento", y desde "gritar" hasta "susurrar".

- Eje de la gestualidad (movimiento corporal:, manos, rostro, mirada)

La gestualidad, en general, puede organizarse en función a su "saturación” o a su "insuficiencia”. Es decir, si se produce demasiada gestualidad del docente (tanta que se vuelve un estorbo en la comunicación), o "muy poca” (incluso un locutor de noticias parpadea y mueve el rostro). El movimiento es parte inevitable de la configuración corporal (de ahí que el cuerpo inerte e inmóvil se asocie a lo muerto o inanimado). El

26 La semiótica discursiva contemporánea abre un campo nuevo al realizar un "giro fenomenológico”, que puede apreciarse desde Greimas, hasta los textos contemporáneos de Fontanille, Zilberberg y otros. 
Aก̃̃ 4- NDי- Dic. 2008

movimiento también está marcado por un ritmo, o, más bien, por un paso ligero o pausado. Este, probablemente acompañe el ritmo antes señalado para la voz.

Cabe anotar que muchos de estos aspectos perceptivos corresponden estrictamente al plano de la expresión (significantes). Como tales, son transparentes para llevar contenidos (significados). En la medida en que se tornan ambiguos, opacan los contenidos y se vuelven ilegibles.

Otro rasgo importante en la gestualidad del docente es la mirada:

"La mirada señala un lugar, una posición; a partir de ahí, el espacio se distribuye en un orden de preferencias y de exclusiones: el espacio se hace político. Hay una mirada directamente relacionada con el orden, es la mirada focal que dirige el entrenamiento de los cuerpos (quien habla, quien actúa) y los centraliza en torno a una figura de poder (todas las miradas confluyen en aquel que detenta el uso de la palabra)” (Tarín 1985: 11)

Es importante señalar que esta toma de posición se marca, entre otras cosas, por la mirada. También interviene, sin embargo, el conjunto entero de la gestualidad; es decir, todo el cuerpo es el teatro de operaciones de una serie de posturas asignadas previamente, como parte de una deóntica (implícita) de la presencia del docente en el aula. En ese sentido:

“(...) el gesto opera como figura en la relación comunicativa: alguien entra en el aula, se sitúa en un lugar previamente asignado y compone un gesto. El emplazamiento, la composición y el catálogo de posibilidades en la dirección de la mirada y la voz señalan la figura de un sujeto que focaliza la atención del grupo. El gesto representa un saber y su circulación, pero más allá de su teatralidad, no hay sino un código que nos informa de su carácter inevitable, de su condición de máscara” (Tarín 1985: 10)

De esta forma, la voz, la mirada, el movimiento, y la gestualidad en general parecen también caer dentro de cierta regulación, no siempre explícita o puesta en evidencia, sino más bien subtendida por la presencia de los estudiantes frente al docente ${ }^{27}$.

27 Tal parece que la precedencia (cronológica) de las estructuras de relación escolar mantiene cierta vigencia en todos los niveles de formación del sistema educativo. 
- Eje de la apariencia física

La apariencia tiene que ver con los rasgos físicos y con la vestimenta. Estos códigos tienen una complejidad que escapa a la reflexión del presente ensayo. Cabe notar que estos códigos no solo son de orden cultural, sino incluso idiolectal,, por sus límites y variaciones en las diversas regiones y grupos humanos: se pueden observar variaciones en el vestir no solo de una universidad a otra, sino, incluso, de una facultad a otra en una misma universidad. Es evidente que, si el docente o el alumno contravienen "las buenas costumbres y los buenos usos” en el vestir, afecta y debilita la construcción de un ser sujeto de credibilidad; por ende, de un "saber" verosímil. De forma contraria, si el uso de vestimenta, así como los rasgos físicos, encajan en parámetros aceptables, el "saber” y el docente no verán mermado el capital del “creer”.

\section{- Ejes afectivos}

La afectividad básica es una inclinación positiva o negativa en la relación con un objeto (de "saber", en el caso educativo): la euforia o disforia ante el objeto o sujeto que se tiene delante.

La afectividad básica está dada por esta inclinación. Son muchos los factores que influyen en este "gusto” o “disgusto”, “placer” o “displacer”. Es posible que un simple rasgo del otro sujeto origine la disforia hacia él. Un alumno puede sentir que un docente "le cae bien” por su timbre de voz o su gestualidad; también puede "caerle mal” por cómo se expresa o cómo maneja la clase.

No obstante, estos son solo algunos elementos sensibles que intervienen en el afecto. La forización de lo otro es también afectada por la intersubjetividad; es decir, que las sanciones y juicios formados sobre el docente, así como sus performances, influyen (y, en ocasiones, regulan) esta afectividad elemental en la captación del otro.

- Eje del "trato" al alumno

En general, por "trato" se entiende el modo en que se produce la relación intersubjetiva entre profesor y alumno. Este estilo de relación puede ir, por ejemplo, desde "hostil”, “cortante” y "áspero" hasta “amigable” "afectuoso” y "paternal”. Es el "aroma” (parafraseando a Greimas y Fontanille) de una combinación de simulacros modales, del ejercicio de las afectividades por medio de la gestualidad, de las variaciones en el uso de la voz, e, incluso, de las sensaciones captadas por la apariencia física del docente. 
Aก̃̃ 4- NDי- Dic. 2008

Por ello, este "trato" es parte del intercambio subjetivo de simulacros, performances y sanciones. Así, cuando el docente reprueba a un alumno, puede hacerlo de un modo áspero u hostil, o de una forma amigable, afectuosa o paternal. El alumno negativamente sancionado siente de modo distinto, a nivel afectivo y emocional, la sanción que realiza el docente sobre su performance.

En este universo de modos en la intersubjetividad, el alumno puede dar expresiones como “tiene razón, mi examen está mal, pero no tiene por qué hacerme sentir como un inútil” o “a pesar de estar reprobado, me trató bien y me dio ánimo para el próximo examen”. Estas expresiones aluden a sanciones negativas en el nivel de performance cognoscitiva, pero con dos tratos diferenciados.

Este "sentir" que "hace”, producido por el docente en el alumno, es general y amplio: no se limita a alguno de los sentidos y, más bien, se vincula a una afectividad proyectada por medio de voces, miradas y gestos.

\section{Efectos sensibles y pasionales}

Como puede apreciarse, en base a la lista previa, las sanciones entre profesor y alumno tienen inevitables ribetes sensibles; muchas veces, son totalmente afectivos y pasionales. Es decir, cualquier conducta del profesor (desde un saludo "seco", hasta una mirada “agresiva” o "tierna”) es percibida y sentida por los alumnos. En consecuencia, producen efectos pasionales en el estudiante.

Cabe señalar que la semiótica ofrece también algunos parámetros para la interpretación y análisis de las pasiones; particularmente, en torno a su recorrido y a las variables tensivas que pueden servir para medir el componente pasional educativo.

El esquema tensivo, propuesto por Fontanille y Zilberberg ${ }^{28}$, es de particular utilidad para estudiar algunas variables de las pasiones:

\footnotetext{
${ }^{28}$ Sobre el tema de la tensividad, existen varios textos publicados por Fontanille y Zilberberg. Se puede revisar la bibliografía para observar algunas publicaciones recientes realizadas por la Universidad de Lima.
} 


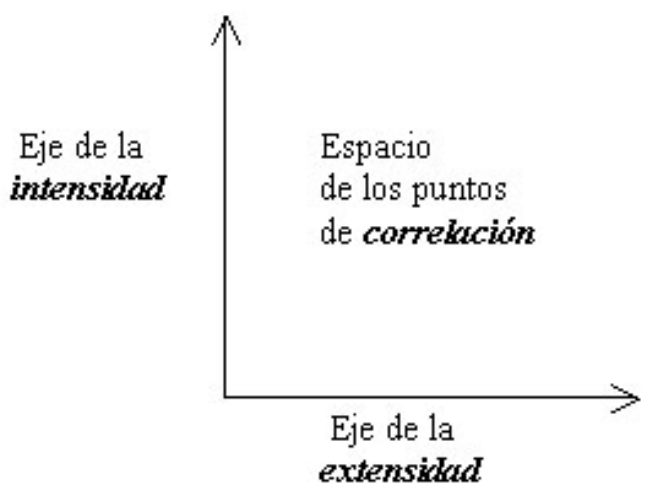

Este esquema pone en relación dos aspectos de cualquier pasión: un aspecto cualitativo (la intensidad) y otro cuantitativo (la extensidad). Es decir, por un lado, un individuo puede sentir una pasión con determinada intensidad, variable según cada uno. Por el otro, cada pasión tiene un aspecto de extensidad, que puede ser (así lo propone la semiótica) tiempo, espacio o cualquier otro aspecto mensurable. Volviendo al ejemplo de la "mirada agresiva" del docente, el nivel de agresividad sería la intensidad; si se repite en reiteradas ocasiones, se aprecia la extensidad. En el mismo ejemplo, puede analizarse el resentimiento correlativo que siente el estudiante como respuesta. Nótese el énfasis puesto en el análisis tensivo, en quién es el individuo que "siente" algo; en este ejemplo, que el estudiante perciba agresividad debido a una o varias miradas, no significa que el docente "sea" realmente agresivo. Lo importante es el enfoque de las pasiones en cuestión.

La única forma de realizar un análisis tensivo (semiótico) de las pasiones, es a través de entrevistas con individuos involucrados en un proceso didáctico. De este modo, se logra un análisis semiótico de los relatos vertidos en dichas conversaciones. Si bien no es un modo directo de aproximación al proceso pedagógico, es tan válido como cualquier otro instrumento para el estudio de procesos de interacción comunicativa y social. Claro está, la entrevista no es muy útil cuando el entrevistado tiene pocas habilidades narrativas, como en el caso de niños o alumnos menores.

\section{Perspectivas}

La semiótica discursiva tiene un importante "grano de arena" que poner en la reflexión sobre el discurso didáctico. Aquí solo se ha esbozado un proyecto que, se espera, pueda entusiasmar mayores profundizaciones, así como fructíferas cooperaciones con otras disciplinas. Se considera, además, que resulta vital investigar el espacio de un salón de clases y las relaciones dadas en el fenómeno educativo. 
Como ha podido apreciarse, la Semiótica Narrativa puede aportar tanto instrumentos de análisis como pautas de integración de diversas perspectivas en el estudio del proceso de interacción profesor-alumno. En tal sentido, la investigación y el análisis semiótico es una necesidad en el campo de las Ciencias de la Educación.

\section{Referencias bibliográficas}

BERTRAND, Denis

2000 Précis de Sémiotique Littéraire. París. Editions Nathan.

BLANCO, Desiderio

1988 "Figuras de la enunciación cinematográfica” En: Lienzo Nº8. Lima, Universidad de Lima.

BLANCO, Desiderio y Raúl BUENO

1980 Metodología del análisis semiótico. Lima, Universidad de Lima.

COURTES, Joseph

1980 Introducción a la semiótica narrativa y discuriva. Buenos Aires, EditorialHachette.

FABBRI, Paolo

1979 "Champ de maneovres didactiques" (Campo de maniobras didácticas) En: Le Bulletin No7, París, Groupe de recherches semioliguistiques (EHESS) y el Institut de la Langue Françaises (CNRS). Traducción de O. Moraña en revista Video Forum No12. México.

FONTANILLE, Jacques

1982 "Un point de vue sur "croire" et "savoir". Les deux systèmes de l'adéquation cognitive”. En: Actes Sémiotiques- Documents. No 33, Paris, Groupe de recherches sémiolinguis-tiques (EHESS) y el Institut de la Langue Française (CNRS).

1987a "Pour changer, commencer par la fin”. En: Le Bulletin No42, París, Groupe de recherches sémiolinguistiques (EHESS) y el Institut de la Langue Française (CNRS).

1987b Le savoir partagé. Sémiotique et théorie de la connaissance chez Marcel Proust. Paris-Amsterdam. Éditions Hadès-Benjamis. 
1993-94 Semiótica de las pasiones. El seminario de Puebla. Morphé 9/10. Revista del Área de Ciencias del Lenguaje. Instituto de Ciencias Sociales y Humanidades. Universidad de Puebla. Puebla.

1998 Sémiotique du Discours. Limoges. Université de Limoges. (Traducción de Oscar Quezada, Semiótica del Discurso, Universidad de Lima. 2000)

FONTANILLE, Jacques y Claude ZILBERBERG

2004 Tensión y Significación. Universidad de Lima. Lima.

GREIMAS, Algirdas Julien

1979 "Pour sémiotique didactique” (Para una semiótica didáctica) En: Le Bulletin No7, París, Groupe de recherches sémiolinguistiques (EHESS) y el Institut de la Langue Française (CNRS). Traducción de O. Moraña en revista Video Forum Nº12. México.

1983 Del Sentido II. Ensayos semióticos. Madrid, Editorial Gredos.

GREIMAS, Algirdas J. Y Joseph COURTES

1982 Semiótica. Diccionario razonado de la teoría del lenguaje. Tomo I. Madrid, Editorial Gredos.

1991 Semiótica. Diccionario razonado de la teoría del lenguaje. Tomo II. Madrid, Editorial Gredos.

GREIMAS, Algirdas J. Y Jaques FONTANILLE

1994 Semiótica de las Pasiones. De los estados de cosas a los estados de ánimo. México, Siglo Veintiuno Editores S.A.

\section{LATELLA, Graciela}

1988 "Proposiciones para una descripción de las prácticas sociales”. En: Investigaciones semióticas II. Simposio Internacional de Semiótica. T II. Oviedo. Universidad de Oviedo.

LANDOWSKI, Eric

1989 La sociedad figurada. Ensayos de sociosemiótica. México. Fondo de Cultura Económica. 
Aก̃̃ 4- NDי- Dic. 2008

\section{MUÑOZ GONZALES, Germán}

1997 “El sujeto de la educación”. En: Nómadas. Comunicación-Educación. Una relación estratégica. Bogotá. Fundación Universidad Central.

QUEZADA, Oscar

1991 Semiótica Generativa. Lima, Universidad de Lima.

RODRÍGUEZ ILLERA, José Luis (comp.)

1988 Educación y comunicación. Barcelona, Ediciones Paidós.

RODRIGUES FARIA CORACINI, Maria José

1994 “O caráter persuasivo da aula de leitura” En: Trabalhos em Lingüística Aplicada. No. 24. Jul-Dez. Campinas. Universidade Estadual de Campinas. Instituto de Estudos de Linguagem.

SMITH-SHANK, Deborah L.

1995 “Semiotic Pedagogy and Art Education”. En. Studies in Art Education: A Journal of Issues and Research, No 36.

STOCKINGER, Peter

1985 "L'actant collectif et l'univers actoriel" En: Le Bulletin $\mathrm{N}^{0} 34$, París, Groupe de recherches sémiolinguis-tiques (EHESS) y el Institut de la Langue Française (CNRS).

TARÍN, Juan José

1995 “Semioanálisis y Crítica. En torno a la relación de enseñanza”. Eutopías, 2 Época. Documentos de trabajo. Vol. 22, Valencia, Centro de Semiótica y Teoría del Espectáculo. Universitat de València.

VINCENSINI, Jean-Jacques

1987 "Prestations éducatives et communica-tion participative”. En: Le Bulletin $\mathrm{N}^{\mathrm{0}} 42$, París, Groupe de recherches sémiolinguistiques (EHESS) y el Institut de la Langue Française (CNRS).

ZILBERBERG, Claude

2000 Ensayos sobre Semiótica Tensiva. Universidad de Lima. Lima.

2006 Semiótica Tensiva. Universidad de Lima. Lima. 
Аก̃̃ 4- ND- Dic. 2008

Para citar este documento, puede utilizar la siguiente referencia:

GARCÍA CONTTO, José (2008). "Para una aproximación de la Semiótica Discursiva a la Intersubjetividad profesor-alumno”. [artículo en línea]. Revista Digital de Investigación en Docencia Universitaria (RIDU) Año 3 $N^{\circ}$ 2-Diciembre 2007. [Fecha de consulta: dd/mm/aa].

$<\underline{\text { http://beta.upc.edu.pe/calidadeducativa/ridu/2008/ridu5 } 5 \text { art3 ig.pdf }>>}$

\section{José David García Contto}

jose.garciacontto@gmail.com

Licenciado en Comunicación de la Universidad de Lima, donde actualmente es docente en los cursos de Semiótica, Análisis del Discurso, Estética y Teorías del Conocimiento. También enseña en la Universidad Peruana de Ciencias Aplicadas el curso de Semiótica Publicitaria, y trabaja además en otras prestigiadas instituciones peruanas.

Realizó estudios de Doctorado en la Universidad de Lovaina (Katholieke Universiteit Leuven) en Ciencias Sociales, al presente continúa su investigación doctoral sobre semiótica y fotografía peruana. 